\title{
Emergency Department Initiatives to Improve the Public Health*
}

\author{
JAMES A. GORDON, MD, MPA, LEWIS R. GOLDFRANK, MD, \\ DENNIS P. ANDRULIS, PHD, ROBERT M. D'AlESSANDRI, MD, \\ ARTHUR L. KELLERMANN, MD, MPH
}

Each year, the Society for Academic Emergency Medicine, the American College of Emergency Physicians, and the American Board of Emergency Medicine co-sponsor an educational session at the Association of American Medical Colleges Annual Meeting. The 1997 session was entitled "Emergency Department Initiatives to Improve the Public Health," and included presentations by 4 invited speakers: Dr. Lewis Goldfrank, Director of Emergency Medicine at Bellevue Hospital Center and New York University Medical Center; Dr. Dennis Andrulis, Director of the Office of Urban Populations at the New York Academy of Medicine; Dr. Robert D'Alessandri, Vice President for Health Sciences and Dean of the School of Medicine at West Virginia University; and Dr. Arthur Kellermann, Acting Chief of Emergency Medicine at Emory University. Each speaker focused on a particular aspect of emergency medicine and the health of the public. The following article summarizes some of the session's ideas and themes.

$\mathrm{T}$ HE ED is uniquely qualified to advocate for total community health. Easily accessible and always open, the ED is one of the few institutions available to help all persons, all the time, without reservation. By embracing a public health approach, emergency medicine (EM) can assume a leadership role in the design and implementation of expanded systems of health and social care.

\section{THE "COMMUNITARIAN" APPROACH TO HEALTH CARE (LEWIS GOLDFRANK)}

Health problems do not exist in a vacuum. Social forces such as poverty, discrimination, homelessness, and substance abuse all contribute to the medical pathology we see in the ED. All too often, however, medical conditions are treated without

From the Section of Emergency Medicine, Department of Surgery, University of Michigan, Ann Arbor, MI, the Robert Wood Johnson Clinical Scholars Program, University of Michigan, Ann Arbor, MI, and the Department of Veterans Affairs, VA Medical Center, Ann Arbor, MI (JAG); the Department of Emergency Medicine, Bellevue Hospital Center and New York University Medical Center, New York, NY (LRG); New York Academy of Medicine, New York, NY (DPA); Office of the Vice President for Health Sciences and Dean, School of Medicine, West Virginia University, Morgantown, WV (RMD); and the Division of Emergency Medicine, Department of Surgery, Emory University, Atlanta, GA (ALK).

Received March 26, 1998; accepted May 15, 1998.

* Based on the Emergency Medicine Session at the American Association of Medical Colleges Annual Meeting, Washington, DC, November 1997.

Address for correspondence and reprints: James A. Gordon, MD, MPA, 6312 Medical Science Building I, 1150 West Medical Center Drive, Ann Arbor, MI 48109-0604. Fax: 734-647-3301; e-mail: jago@umich.edu regard to their social context. To truly help our most vulnerable ED patients, we must understand that meaningful health care encompasses more than just medical service-it requires attention to those social and community circumstances that are inexorably linked to overall well-being.

Public health initiatives have resulted in remarkable health benefits for ED patients. Whereas children previously sustained serious alkali burns or pneumonitis from household ingestions, community efforts to reduce chemical concentrations, alter packaging and delivery systems, educate parents, and market household safety products have noticeably reduced the severity and incidence of chemical ingestion injuries. Hot water thermostats alone have prevented countless burn injuries, and fluoridated water has significantly affected dental health. Highways are safer due to preventive engineering and public education campaigns, and immunization schedules have all but wiped out many lethal diseases. Thiamine administration to alcoholic individuals is now commonplace. Millions breathe easier because of engine emission standards, and tuberculosis screening and treatment programs have prevented extensive outbreaks.

For medical treatment to have the far-reaching impact of many public health programs, we must integrate social and public health concerns into daily treatment plans, especially in the ED. Education, housing, transportation, day care, and employment all must be considered when treating the patient. A $\$ 2.00$ prescription for penicillin is worthless to the person who has nothing to spend. And while the ED cannot be all things to all people, it is perhaps the best institutional barometer of social and public health failures. As physicians at the 
interface of medicine and society, we are obligated to broaden our view of total health, and to identify creative, humanistic approaches to patient care.

\section{EDs AND THE PUblic SECTOR CRISIS} (DENNIS ANDRULIS)

In the midst of global restructuring of our health care system, ED visits have risen to over 90 million per year. Perhaps because the most disadvantaged patients are still seen in EDs across the country, an ED visit is often viewed as a "failure" of the health care system, rather than an integral part of it. Discussions of "worthy" and "unworthy" ED patients frequently obscure medicine's fundamental mission to provide unconditional comfort and care. As the last repository of unquestioned care, especially in safety-net hospitals, the ED now finds itself at the center of a debate on public responsibilities toward community health.

With private hospital ED visits growing even faster than public hospital ED visits, the role of the public sector in providing a health care safety net is becoming more unclear. Until recently, indigent health care was largely financed by the government through public hospitals and clinics; the private sector had tended away from vulnerable populations as a fiscal risk. With the privatization of health care, especially under Medicaid managed care, the private sector now finds itself competing to attract patients it once shunned. The result is often a critical loss of patients and Medicaid revenue for public hospitals and EDs, calling into question their fiscal viability and very reason for existence.

Public sector responsibility for community health will ultimately be redefined in one of 3 ways. In a fully-vested public sector, public hospitals and providers will compete with private counterparts for all patients and contracts, including Medicaid contracts, and will try to develop publicprivate partnerships or consortia. The major public-sector health system in Colorado, Denver Health, is developing along this model, operating as a "public benefit corporation" to avoid the constraints of government bureaucracy while maintaining the service objectives and patient base of a public system. In a residual public sector, the public hospital system will provide charity care only to the most vulnerable patients, leaving all other care to the private market. In a divested public sector, all care will be provided privately, leaving existing public hospitals to close, merge, or be sold into the private sector. A modified such model is currently being tested in Milwaukee.

The prevailing scenario in any one community will depend on how local leaders decide to allocate resources and establish regulatory constraints.
Such a process will entail a fundamental reevaluation of the public sector's role in community health. Leaders will have to define the "greater good" in the local market, and decide who, if anyone, should provide for it. Such a process will inherently involve consideration of the hospital ED, not only as an efficient site of unrestricted medical care, but also as an integral component of the local health and welfare system.

\section{Public Health AND ACADEMIC EMERGENCY MEDICINE (ROBERT D'ALESSANDRI)}

One solution to the public sector health care crisis can be found in the state-supported academic medical center. Although the modern medical school was advanced as a center of science and clinical training, the Flexner report also described the medical school as "a public service corporation ... chartered by the state ... [which] utilizes public hospitals on the ground of the social nature of its services." All too often, however, contemporary medical schools have lost sight of their fundamental public service mission, producing scientific specialists rather than community-minded physicians. The ideal physician, according to a profile developed by the Canadian Royal College of Physicians and Surgeons, is not only a medical expert, but also a communicator, collaborator, manager, health advocate, scholar, and professional. The academic medical center, moreover, is not merely a national research and training center, but an important community resource that must remain responsive to local needs.

At the request of the state legislature, the West Virginia University School of Medicine has tried over the past several years to reinvent itself as a "public service corporation," paying particular attention to EM and injury control. Although this rural state has a very high rate of serious motor vehicle collisions and occupational injuries, many areas do not offer even basic emergency medical services (EMS). The EMS system is predominantly staffed by volunteers, and coverage varies widely by locale. In one county, two 75-year-old women are the only paramedics available to provide services during the day!

To help improve emergency and trauma care in rural areas, the Medical School and Department of Emergency Medicine have collaborated to form the Center for Rural Emergency Medicine (CREM), and the Injury Control Training Demonstration Center. CREM was designed to develop model curricula and educational programs using innovative technology such as telemedicine; to conduct highquality research on the etiology, risk factors, and prevention of acute morbidity and mortality in ru- 
ral areas; and to serve as a state and national resource for information and programmatic assistance on rural EM issues. In association with CREM, the CDC sponsors the Injury Control Training Demonstration Center, designed to reduce injury-related morbidity and mortality through a cohesive statewide injury control program. This program provides public and provider training on injury control and acute care, generates applied research to guide the direction of community-based injury control activities, and offers a variety of local and national information resources.

State medical schools have a responsibility to address state needs. When the state legislature called on West Virginia University to help address state and local public health concerns, the Medical School responded. As the health system continues to change, academic medical centers must continue to strive toward public service. "The University," said University of Arkansas Chancellor Charles Hathaway, "must not stand apart from its society and its immediate environment, but must be an integral part of that society."

\section{EM AS A "Front Line" of PubliC HEALTH (ARTHUR KELLERMANN)}

The ED embodies the highest ideals of public service. Providing unrestricted care 24 hours a day, 7 days a week, the ED is a social and health care safety net in many communities. The health status of an entire population is often reflected in the activity of a single ED, making EM a truly publichealth-oriented field. As practitioners, we have a responsibility to operationalize EDs as integral components of the country's health and social welfare system.

Emergency departments are particularly wellsuited to serve as surveillance centers for largescale public health problems such as injury prevention and infectious disease control. The Weapons Related Injury Surveillance System (WRISS) in Massachusetts and the "Cops and Docs" program in Atlanta are 2 examples of EDs partnering with state and local agencies to provide population-based firearms injury data. Other EDs have concentrated on issues of domestic violence or transportation safety, while the Emerging Infections Sentinel Network (EMERGEncy ID NET) has recently been established to organize selected EDs into a national screening network for infectious disease.

For EM to truly have an impact on public health, practitioners must assume "ownership" of important public health issues they see every day. Emergency physicians can take the lead in educating medical students and residents, as well as the public, on the need for communitywide efforts at disease prevention and health promotion. Most important, however, may be the public health initiatives that begin one patient at a time, with crucial "whispered words" woven into an ED encounter: "wear your seat belt . . . stop smoking ... don't drink and drive." Ours is a unique responsibility at the critical interface between medicine and public health.

\section{Further Thoughts from the Reviewers}

In this summary of the EM session at the AAMC 1997 Annual Meeting, the authors call on EM to help identify and solve social and public health problems. This is not the first such "call to action." However, this summary provides examples of successful collaborations between EM and public health and provocative ideas for linking EDs more closely to the community. These ideas include broadening "our view of total health," developing curricula using telemedicine to decrease morbidity and mortality in rural areas, and serving as "surveillance centers for large-scale prevention and infectious disease programs." By "advocating" for public health (in teaching programs, for example), by conducting public-healthtype surveillance (the authors mention infectious disease and injury surveillance systems), by helping individual patients (brief reminders to "stop smoking" or "wear your seat belt"), and by operationalizing EDs as critical components of the health and social welfare system, emergency care providers can address many public and social health needs.

However, many questions remain. How can EDs begin to help in areas of specific social concerns such as poverty, lack of education, and homelessness? How, when, and by whom will these issues be addressed, and who will pay?

The EM community has been challenged by these issues; our responses will help shape our clinical and academic environment in the years to come. 